\title{
Agregação de Latossolo Vermelho sob diferentes sistemas de preparo do solo, após um único cultivo com girassol
}

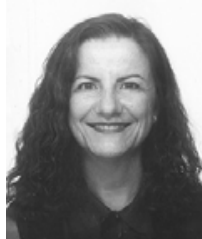

Maria R. G. Ungaro ${ }^{1}$, Afonso Peche Filho², Antonio C. L. Lino ${ }^{2}$, Aildson P. Duarte ${ }^{3}$

1 APTA-CEGRAFI/IAC, Av. Barão de Itapura, 1481, CEP 13001-970. Campinas, SP, CP 28, Fone: (19) 3241-5188, Ramal 320. E.-mail: ungaro@iac.br. Bolsista do CNPq. (Foto)

2 APTA-CEA/IAC, Rodovia Dom Gabriel,km 65, CP 26, CEP 13201-970, Jundiaí, SP. E.-mail: peche@terra.com.br

${ }^{3}$ APTA, Polo Regional do Vale do Paranapanema, CEP 19813-000, Assis, SP. E.mail: aildson@femanet.com.br

Protocolo 193 - 18/12/2002 - Aprovado em 29/10/2004

\begin{abstract}
Resumo: Avaliou-se, no presente trabalho, o efeito de um único cultivo de girassol na agregação de Latossolo Vermelho submetidos a diferentes sistemas de preparo, em número de quatro: grade aradora + grade niveladora (GA), grade niveladora (GN), semeadura direta na palha (SP) e plantio direto (PD), no outono-inverno; exceto no PD, foi passado o escarificador + grade niveladora na primavera-verão semeando-se, em seguida, a soja e, no outono-inverno o girassol. As avaliações dos agregados de solo foram feitas antes do plantio e após a colheita do girassol, em propriedades particulares em Cândido Mota e Pedrinhas Paulista, SP, cujo cultivo do girassol melhorou a agregação, independentemente do sistema de preparo utilizado.
\end{abstract}

Palavras-chave: propriedade física, agregação do solo

\section{Soil aggregation of Red Latosols under different tillage systems after sunflower cropping}

\begin{abstract}
The objective of the present research was to evaluate the effect of single sunflower crop on soil aggregation under different tillage systems. Four tillage systems were used: heavy disk harrow + leveling harrow (GA), leveling harrow (GN), sowing on straw (SP) without tillage (PD), in the autumn-winter, and chisel plow + leveling harrow in the spring-summer cultivation, except for PD treatment. The research was conducted under field conditions in Candido Mota and Pedrinhas Paulista, Sao Paulo State. Soybean was sowed in the spring-summer season and sunflower in the autumn-winter. The soil aggregates were evaluated before sowing and after sunflower harvest. The use of sunflower crop induced a better soil aggregation in both places, for all tillage systems.
\end{abstract}

Key words: physical properties, soil aggregation

\section{INTRODUÇÃO}

Quando se analisa o solo para fins de produção agrícola, a fertilidade é a propriedade que recebe maior atenção, mas outras, como textura, estrutura, capacidade de troca de cátions e compactação, podem ser de suma importância se o objetivo é maximizar a produção; além de características intrínsecas do solo, o rendimento de uma cultura depende do manejo do solo e do manejo cultural, uma vez que a escolha adequada da sucessão/rotação de culturas deve contribuir para a melhoria das condições de cultivo e conseqüente aumento de renda da propriedade.

O preparo de solo pode alterar bastante o espaço poroso, que é importante na movimentação do ar e da água e no crescimento das raízes. Variações de solo e clima, bem como tipos distintos de implementos e condições de umidade do solo durante o preparo, acarretam condições de porosidade diferentes (Eltz et al., 1989). Em geral, o cultivo convencional promove inicialmente aumento da macroporosidade e da porosidade total e diminuição na microporosidade e densidade do solo (Fernandes et al., 1983), favorecendo a germinação e o desenvolvimento das plantas. No sistema plantio direto há tendência ao adensamento da camada superficial, resultado do aumento da densidade do solo e da microporosidade (Abraão et al., 1979). Por sua vez, Bezerra (1978) verificou que o arado de discos e a grade pesada promoveram maiores diminuições no tamanho dos agregados que o sistema plantio direto.

Vieira (1981) observou diminuição da macroporosidade do solo no sistema plantio direto, na camada de até $15 \mathrm{~cm}$, quando comparado ao sistema convencional, após quatro anos de implantação dos dois sistemas. 
No geral, os trabalhos enfocam possíveis alterações na física do solo como conseqüência de práticas, por exemplo diferentes sistemas de manejo, que são utilizados por um tempo tal que as pequenas modificações se acumulam e acabam sendo estatisticamente significativas ou mesmo mensuráveis. Não é comum encontrar-se trabalhos que estudem mudanças nas características físicas do solo causadas por um único ciclo de uma cultura qualquer, simplesmente porque essas mudanças são geralmente sutis e cumulativas.

Silva \& Ribeiro (1992) estudaram o cultivo continuado da cana-de-açúcar em solos argilosos, durante 25 anos, e verificaram que não houve modificação expressiva nas características do solo, em profundidade. No entanto, uma análise dos resultados apresentados mostra progressiva tendência a aumento na porcentagem de agregados menores na camada BA, com diminuição progressiva de agregados entre 1 e $2 \mathrm{~mm}$ de diâmetro. Por seu lado, após um único cultivo de girassol, Ungaro et al. (2000) e Ungaro et al. (2002) encontraram melhoria na agregação e diminuição na resistência à penetração das raízes, em área de rotação de culturas e reforma de canavial, respectivamente.

Autores como Hagin (1952) já afirmavam que agregados maiores oferecem melhores condições para o desenvolvimento das plantas, e Queiroz Neto et al. (1966) encontraram que os agregados entre 1 e $4 \mathrm{~mm}$ favoreciam o crescimento do milho.

Freire \& Piedade Jr. (1979) propuseram a utilização do Módulo de Finura dos agregados, calculado a partir dos dados de peneiramento das amostras de solo a seco, como parâmetro para expressar a estabilidade dos agregados do solo. De acordo com Chepil citado por Freire \& Piedade Jr. (1979), a estabilidade mecânica dos agregados secos é um índice muito mais preciso da estrutura natural do solo de que a estabilidade dos agregados em água.

A ação das plantas na formação e estabilidade dos agregados é ressaltada por vários pesquisadores. Entre as plantas, as gramíneas vêm apresentando efeito positivo na agregação. Também, é sabido que os diferentes sistemas de manejo exercem seus efeitos na formação dos agregados de forma diferenciada e que, dependendo da cultura e do preparo de solo, esses efeitos serão maiores ou menores em termos de estruturação ou degradação (Carpenedo \& Mielnicsuki, 1990; Paladini \& Mielnicsuki, 1991).

Sob condições tropicais ocorre uma carência muito grande de informações a respeito do girassol, como parte integrante de diferentes sistemas de manejo. A tecnologia de produção do girassol existente está baseada, em grande parte, em trabalhos desenvolvidos sob condições de clima temperado e em solos com características bastante diferentes dos nossos.

O presente trabalho teve por objetivo avaliar o efeito de um único cultivo com girassol na agregação de dois Latossolos vermelhos, submetidos a diferentes sistemas de preparo do solo.

\section{MATERIAL E MÉTODOS}

$\mathrm{O}$ ensaio foi delineado no esquema de blocos ao acaso, com 5 repetições, instalado em áreas de Latossolo Vermelho da Coopermota, em Cândido Mota, e em Pedrinhas Paulista, SP. A Tabela 1 apresenta os resultados da caracterização granu-
Tabela 1. Caracterização granulométrica dos solos de Cândido Mota e Pedrinhas Paulista, em duas profundidades de amostragem

\begin{tabular}{|c|c|c|c|c|c|}
\hline \multirow{4}{*}{$\begin{array}{l}\text { Classe } \\
\text { textural }\end{array}$} & \multirow{4}{*}{$\begin{array}{l}\text { Limites da } \\
\text { classe }(\mathrm{mm})\end{array}$} & \multicolumn{4}{|c|}{ Distribuição de partículas (\%) } \\
\hline & & Cândi & o Mota & Pedrinhas & aulistas \\
\hline & & \multicolumn{4}{|c|}{ Profundidades $(\mathrm{cm})$} \\
\hline & & $0-15$ & $15-30$ & $0-15$ & $15-30$ \\
\hline Cascalho & 2,0 & 0 & 0 & 0 & 0 \\
\hline Areia gross & $2,($ & 2,8 & 2,5 & 7,0 & 5,7 \\
\hline Areia fina & 0,2 & 7,9 & 6,2 & 10,8 & 9,5 \\
\hline Silte & $0,05-0,002$ & 20,1 & 15,2 & 11,7 & 11,4 \\
\hline Argila & $<0,002$ & 69,2 & 76,1 & 70,5 & 73,4 \\
\hline
\end{tabular}

lométrica realizada nos dois locais em que foram instalados os experimentos, em duas profundidades de amostragem. Observase que, independentemente do local e da profundidade de amostragem, as áreas são classificadas como muito argilosas, apresentando mais de $60 \%$ de argila em todas as amostras. Não há diferença textural nas duas áreas, no que se refere à profundidade de coleta, mas se pode observar que o solo de Pedrinhas Paulista apresenta menos silte e maior quantidade de areia que o de Cândido Mota.

Os tratamentos constaram, no verão, de uso do escarificador seguido por gradagem, exceto no plantio direto. No plantio de outono-inverno, os tratamentos foram grade aradora + grade niveladora (GA), grade niveladora (GN), semeadura na palha (SP) e plantio direto (PD).

No plantio de verão de 1995 foi cultivada a soja e, no de outono-inverno de 1996, o girassol cv. Cargill 11. As parcelas tiveram área útil de $48 \mathrm{~m}^{2}$. Após a colheita da soja e do girassol, foram realizadas avaliações da agregação do solo em duas profundidades, $0-15 \mathrm{~cm}$ e $15-30 \mathrm{~cm}$, a partir da retirada de três amostras de solo por parcela, que foram colocadas em bandejas para secagem ao ar, até peso constante. Depois de seco, cada amostra por parcela, de aproximadamente $100 \mathrm{~g}$ de solo, foi peneirada em um jogo de quatro peneiras, resultando em cinco classes de tamanho de agregados, em $\mathrm{mm}$, a saber: $>2,00$; entre 1,00 e 2,00; entre 0,50 e 1,00 ; entre 0,25 e 0,$50 ;<0,25$. Após pesagem, obteve-se o peso dos agregados para cada classe.

\section{RESULTADOS E DISCUSSÃO}

Na Tabela 2 tem-se os dados relativos à análise estatística conjunta, para os dados de porcentagem de agregados. Constatou-se diferença estatisticamente significativa entre locais, épocas de amostragem, profundidade de amostragem e as interações envolvendo esses três fatores para a porcentagem de agregados maiores que 2,0 $\mathrm{mm}$; aqueles com diâmetro entre 1,0 e 2,0 $\mathrm{mm}$ e para os agregados menores que $0,25 \mathrm{~mm}$. O fator preparo e as interações com local, época e profundidade, foram não-significativos para todas as variáveis analisadas, indicando que o tipo de mobilização, ou a sua ausência no caso do PD, não teve influência sobre a agregação do solo. A inexistência de diferença entre os sistemas de preparo adotados e suas interações com os demais fatores se deve, muito provavelmente, 
Tabela 2. Análise estatística conjunta dos dois locais, dos dados de \% de agregados menores que $0,25 \mathrm{~mm}$ e maiores que $2,0 \mathrm{~mm}$

\begin{tabular}{|c|c|c|c|c|c|c|}
\hline \multirow[b]{2}{*}{ Causas da variação } & \multirow[t]{2}{*}{ G.L } & \multicolumn{5}{|c|}{ Quadrados Médios } \\
\hline & & $>2,0 \mathrm{~mm}$ & $1,0-2,0 \mathrm{~mm}$ & $0,5-1,0 \mathrm{~mm}$ & $>0,25 \mathrm{~mm}$ & $<0,25 \mathrm{~mm}$ \\
\hline Local & 1 & $102,7^{* *}$ & $25,3^{*}$ & $7,7^{\mathrm{ns}}$ & $32,0 *$ & $273,6^{* *}$ \\
\hline Época & 1 & $260,6^{* *}$ & $80,5 * *$ & $6,6^{\mathrm{ns}}$ & $14,5^{\mathrm{ns}}$ & $604,9 * *$ \\
\hline Local x Época & 1 & $130,2^{* *}$ & $47,5 * *$ & $4,0^{\mathrm{ns}}$ & $35,5^{*}$ & $86,2 * *$ \\
\hline Profundidade & 1 & $11107,3^{* *}$ & $146,9^{* *}$ & $38,4^{* *}$ & $369,3^{* *}$ & $148,5^{* *}$ \\
\hline Local x Profundidade & 1 & $60,7^{*}$ & $4,3^{\text {ns }}$ & $8,0^{\mathrm{ns}}$ & $29,5^{*}$ & $0,02^{\mathrm{ns}}$ \\
\hline Época x Profundidade & 1 & $90,8^{*}$ & $25,9^{*}$ & $0,1^{\mathrm{ns}}$ & $24,3^{\mathrm{ns}}$ & $126,7^{* *}$ \\
\hline Local x Época x Profundidade & 1 & $100,6^{*}$ & $13,7^{\mathrm{ns}}$ & $0,003^{\text {ns }}$ & $14,4^{\mathrm{ns}}$ & $61,9^{*}$ \\
\hline Preparo & 3 & $13,8^{\mathrm{ns}}$ & $2,3^{\text {ns }}$ & $2,8^{\mathrm{ns}}$ & $7,7^{\mathrm{ns}}$ & $3,8^{\text {ns }}$ \\
\hline Local x Preparo & 3 & $7,1^{\mathrm{ns}}$ & $1,1^{\mathrm{ns}}$ & $1,2^{\mathrm{ns}}$ & $0,2^{\mathrm{ns}}$ & $11,6^{\mathrm{ns}}$ \\
\hline Época x Preparo & 3 & $14,9^{\mathrm{ns}}$ & $4,0^{\mathrm{ns}}$ & $4,4^{\mathrm{ns}}$ & $2,2^{\mathrm{ns}}$ & $9,1^{\text {ns }}$ \\
\hline Profundidade x Preparo & 3 & $4,6^{\mathrm{ns}}$ & $8,3^{\text {ns }}$ & $7,3^{\text {ns }}$ & $6,0^{\mathrm{ns}}$ & $3,3^{\mathrm{ns}}$ \\
\hline Local x Época x Preparo & 3 & $48,4^{*}$ & $10,7^{\mathrm{ns}}$ & $5,8^{\mathrm{ns}}$ & $20,1^{*}$ & $34,2 *$ \\
\hline Local x Profundidade x Preparo & 3 & $8,5^{\text {ns }}$ & $7,6^{\mathrm{ns}}$ & $1,7^{\mathrm{ns}}$ & $4,7^{\mathrm{ns}}$ & $3,9^{\mathrm{ns}}$ \\
\hline Época x Profundidade x Preparo & 3 & $5,7^{\mathrm{ns}}$ & $4,4^{\mathrm{ns}}$ & $0,9^{\mathrm{ns}}$ & $2,7^{\mathrm{ns}}$ & $0,8^{\mathrm{ns}}$ \\
\hline Local x Época x Profundidade x Preparo & 3 & $16,7^{\mathrm{ns}}$ & $4,1^{\mathrm{ns}}$ & $6,8^{\mathrm{ns}}$ & $2,1^{\mathrm{ns}}$ & $11,0^{\mathrm{ns}}$ \\
\hline Resíduo & 124 & 14,8 & 4,3 & 3,6 & 6,5 & 11,4 \\
\hline CV\% & & 14,4 & 7,9 & 6,9 & 9,9 & 13,1 \\
\hline
\end{tabular}

ao pequeno intervalo de tempo entre a adoção dos diferentes sistemas de preparo do solo e a tomada dos dados de solo.

A diferença entre locais já era esperada, uma vez que as características do solo são ligeiramente diferentes entre Cândido Mota e Pedrinhas, o que concorre para respostas diferenciadas. No entanto, a diferença altamente significativa entre as épocas de amostragem mostra a capacidade do girassol em alterar a distribuição de agregados do solo. Uma resposta dessa natureza, após um único cultivo, não era esperada, uma vez que são necessários alguns anos com determinada prática ou cultura para que as diferenças possam ser detectadas estatisticamente. $O$ curto espaço de tempo entre a amostragem inicial e a final explica a ausência de diferença estatística entre os distintos preparos de solo. A interação entre local e época reflete a resposta ligeiramente distinta encontrada entre os dois locais, após o cultivo com girassol.

A variação na distribuição dos agregados do solo de Cândido Mota e de Pedrinhas, em duas profundidades, após o cultivo de girassol, pode ser observada nas Figuras 1 e 2, as quais representam a diferença entre os valores encontrados nas duas profundidades de amostragem, antes e após o cultivo com girassol. Pode-se notar sensível diminuição dos agregados menores que $0,25 \mathrm{~mm}$, em ambas as localidades e nas duas profundidades de amostragem, após o cultivo do girassol. Em Pedrinhas Paulista ocorreu, ainda, um aumento considerável na porcentagem de agregados maiores que $2,00 \mathrm{~mm}$, em ambas as profundidades mais acentuadamente na camada $0-15 \mathrm{~cm}$.

Ungaro et al. (2002) também encontraram aumento na proporção de agregados de maior tamanho e diminuição dos menores após um único cultivo de girassol, porém em argissolo.

Observando-se as Figuras 1 e 2, é possível se ter uma idéia das alterações da agregação após cultivo com girassol, sob diferentes sistemas de mobilização do solo, cujos resultados são apresentados em porcentagem referente à observação

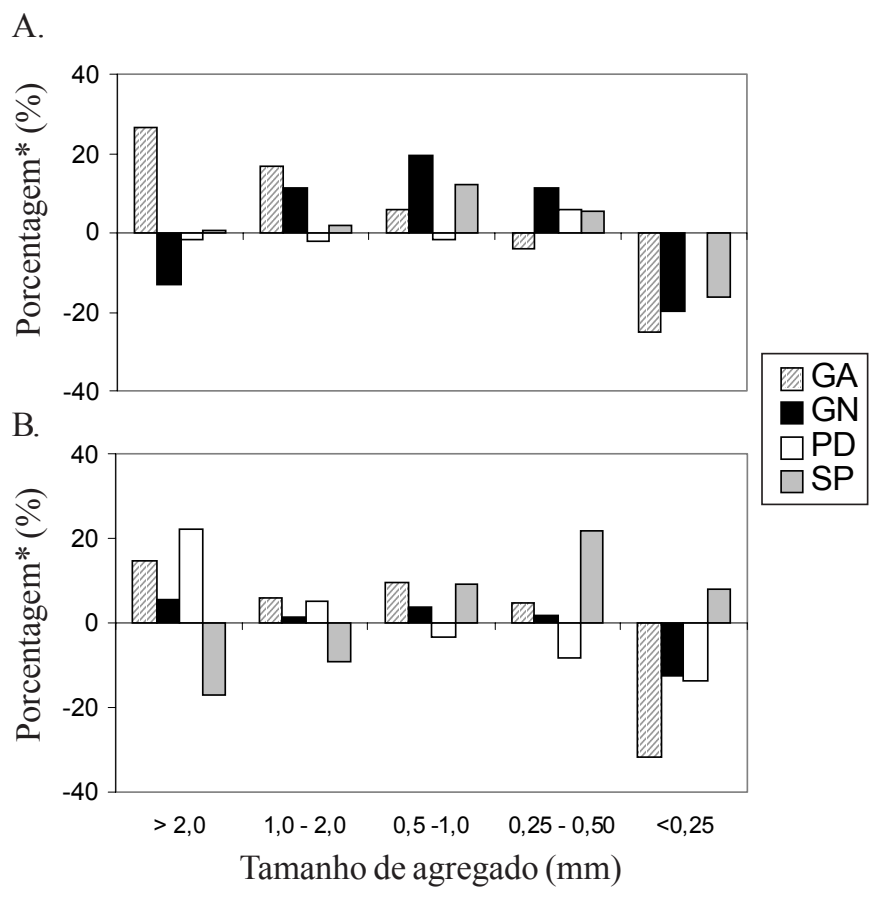

* Diferenças em relação à avaliação anterior ao cultivo de girassol

Figura 1. Variação percentual na distribuição dos agregados nas camadas (A) 0-15 cm e (B) 15-30 cm em um Latossolo Vermelho de -A.Cândido Mota, nos sistemas de preparo com grade aradora (GA), grade niveladora (GN), plantio direto (PD) e semeadura na palha (SP).

inicial, antes do plantio de girassol. Em Cândido Mota, na profundidade $0-15 \mathrm{~cm}$ (Figura 1A) houve diminuição dos agregados menores que $0,25 \mathrm{~mm}$ para os tratamentos $\mathrm{GA}, \mathrm{GN}$ e SP, com aumento acentuado dos agregados maiores que 2,00 $\mathrm{mm}$ para o tratamento GA; na profundidade $15-30 \mathrm{~cm}$ (Figura 1B) os resultados mostram incremento na porcentagem de 
A.

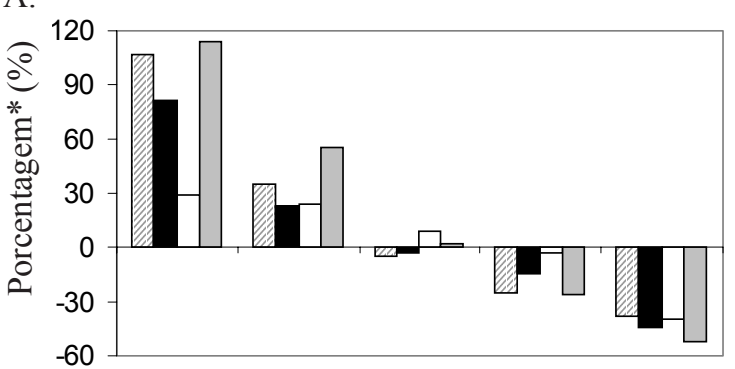

B.

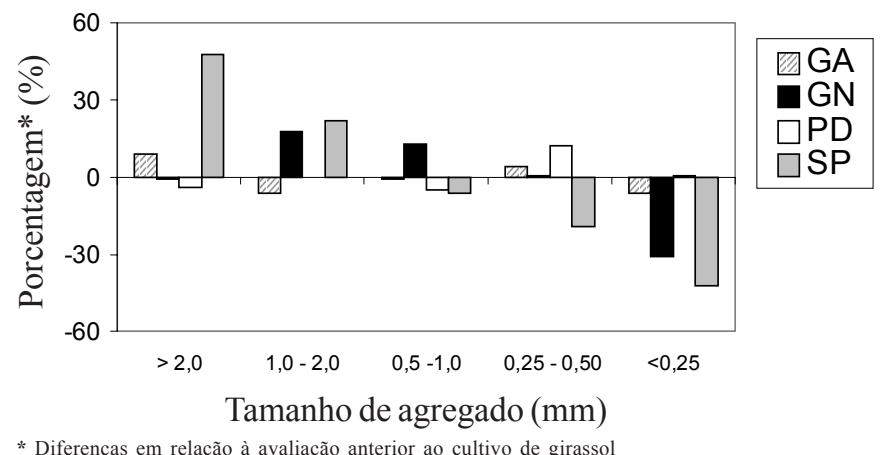

* Diferenças em relação à avaliação anterior ao cultivo de girassol

Figura 2. Variação percentual na distribuição dos agregados nas camadas (A) $0-15 \mathrm{~cm}$ e (B) $15-30 \mathrm{~cm}$ em um Latossolo Vermelho de Pedrinhas Paulista, nos sistemas de preparo com grade aradora (GA), grade niveladora $(\mathrm{GN})$, plantio direto (PD) e semeadura na palha (SP).

agregados maiores que 2,0 mm e diminuição dos menores que $0,25 \mathrm{~mm}$, com exceção para o tratamento SP. Em Pedrinhas (Figura 2A e B) o aumento foi muito grande na porcentagem de agregados maiores que $1,0 \mathrm{~mm}$ e conseqüente diminuição dos agregados menores que $0,5 \mathrm{~mm}$, na profundidade $0-15 \mathrm{~cm}$; na camada 15-30 cm, alterações mais significativas foram encontradas no tratamento SP, sendo que nos demais sistemas praticamente não houve modificação na distribuição dos agregados.

Apesar das diferenças entre os parâmetros de solo avaliados para os sistemas de preparo não terem sido estatisticamente significativas, as Figuras 1 e 2 mostram a tendência do comportamento dos agregados do solo antes e após o cultivo com girassol, nas duas profundidades de amostragem. Stone \& Silveira (1999) em trabalho semelhante a este, utilizando a média de vários anos para os parâmetros porosidade e densidade do solo, já que a tendência das propriedades físicas foi semelhante ao longo dos anos. Eles encontraram que resultados obtidos durante uma avaliação realizada no decorrer do mesmo, foram suficientes para detectar a tendência de comportamento dos parâmetros com os tratamentos realizados. Extrapolando para a presente pesquisa, parece haver tendência à melhoria na agregação nos tratamentos GA e GN em Cândido Mota, nas duas profundidades de amostragem, e no tratamento SP, seguido pelo GA, na profundidade $0-15 \mathrm{~cm}$, e em SP na profundidade $15-30 \mathrm{~cm}$, no solo de Pedrinhas Paulista, como exposto nas Figuras 1 e 2.

Harris et al. (1966), discutem que a ênfase na agregação de solo realizada pelas culturas está centrada no papel exercido pela extensa rede de raízes, originando os agregados. As raízes em crescimento podem excretar substâncias que por sua vez, poderão agir como agentes ligantes. $\mathrm{O}$ efeito agregador do girassol pode ser explicado pela estrutura de seu sistema radicular, que é do tipo pivotante, podendo alcançar até mais de 2,0 $\mathrm{m}$ de profundidade. Na camada superficial do solo ocorre o desenvolvimento de inúmeras e bem desenvolvidas raízes laterais, ricas em lignina, que se distribuem por 60 a $150 \mathrm{~cm}$, ocupando principalmente os primeiros $30 \mathrm{~cm}$ de solo (Carter, 1978). As raízes de girassol absorvem grande quantidade de água de tal modo que pode causar desidratação do solo que, por sua vez, causa fendas ao encolher, originando rompimentos e formação de agregados. De acordo com Hénin et al. (1976) o tamanho médio dos elementos estruturais obtidos é função da densidade de implantação das raízes na camada de solo em questão. Esses autores também teceram considerações sobre o papel do bom desenvolvimento do raizame superficial para o melhoramento das propriedades estruturais, e das raízes pivotantes como exploradoras de fendas existentes nas camadas inferiores do solo, ampliando-as e estabilizando-as concorrendo,assim, para o melhoramento do perfil do solo.

É possível admitir que o efeito mais acentuado do cultivo de girassol aumentando a agregação do solo em Pedrinhas Paulista, seja pela condição textural desta área, que apresenta na sua composição uma quantidade menor de silte e, consequentemente, maior quantidade de areia, favorecendo um enraizamento melhor da cultura; já o Latossolo de Cândido Mota apresenta mais silte, menos areia e praticamente a mesma quantidade de argila, ou seja, é um solo mais pesado, o que concorreria para menor desenvolvimento radicular, com reflexos na agregação do solo.

\section{CONCLUSÕES}

1. Para Latossolos Vermelhos, um único cultivo de girassol pode ser suficiente para melhorar o estado de agregação, pela diminuição dos agregados menores que $0,25 \mathrm{~mm}$, independentemente do sistema de preparo adotado.

2. A intensidade da agregação depende das características texturais do solo utilizado.

\section{LITERATURA CITADA}

Abrão, P.U.R.; Goepfert, C.F.; Guerra, M.; Eltz, F.L.F.; Cassol, E.A. Efeitos de sistema de preparo do solo sobre características de um Latossolo Roxo distrófico. Revista Brasileira de Ciência de Solo, Campinas, v.3, n.3, p.169-72, 1979.

Bezerra, J.E.S. Influência do sistema de manejo do solo sobre algumas propriedades físicas e químicas de um Podzólico Vermelho-Amarelo Câmbico distrófico, fase terraço e sobre a produção de milho. Viçosa: UFV, 1978, 61p. Dissertação Mestrado

Carpenedo, V.; Mielnicsuki, J. Estado de agregação e qualidade de agregação de agregados de Latossolos Roxos submetidos a diferentes sistemas de manejo. Revista Brasileira de Ciência de Solo, Campinas, v.14, p.99-105, 1990. 
Carter, J.F. Sunflower Science and Technology. Madison: American Society of Agronomy, 1978. 375p. Agronomy Monograph, 19

Eltz, F.L.F.; Peixoto, R.T.G.; Jaster, F. Efeitos de sistemas de preparo do solo nas propriedades físicas e químicas de um Latossolo Bruno álico. Revista Brasileira de Ciência de Solo, Campinas, v. 13, n. 2, p. 259-267, 1989.

Fernandes, B.; Galloway, H.M.; Bronson, R.D.; Mannering, J.V. Efeitos de três sistemas de preparo do solo na densidade aparente, na porosidade total e na distribuição de poros, em dois solos (Tipic Argiaquoll e Tipic Hapludalf). Revista Brasileira de Ciência de Solo, Campinas, v.7, n.3, p.329-33, 1983.

Freire, W.J.; Piedade Jr., C. O módulo de finura dos agregados do solo como um índice de estabilidade estrutural. Engenharia Agrícola, Botucatu, v.3, n.2, p.29-36, 1979.

Hagin, J. Influence of soil aggregation on plant growth. Soil Science, Baltimore, v.74., n. 6, p.471-478, 1952.

Harris, R.F.; Chesters, G.; Allen, O.N. Dynamics of soil aggregation. Advances in Agronomy, Ann Harbor, v.18, p.107-169, 1966 .

Paladini, F.L.S.; Mielniczuk, J. Distribuição de tamanho de agregados de um solo Podzólico vermelho-escuro afetado por sistema de culturas. Revista Brasileira de Ciência do Solo, Campinas, v. 15, p.135-140, 1991.
Queiroz Neto, J.P.; Grohman, F.; Oliveira, J.B. Características analíticas dos agregados dos solos terra-roxa (Latossolo Roxo) e Massapé (Podzólico Vermelho Amarelo-Orto). Bragantia, Campinas, v.25, n.41, p.457-476, 1966.

Silva, M.S.L.; Ribeiro, M.R. Influência do cultivo contínuo da cana-de-açúcar em propriedades morfológicas e físicas de solos argilosos de tabuleiro no Estado de Alagoas. Revista Brasileira de Ciência do Solo, Campinas, v.16, n.3, p.397-402, 1992.

Stone, L.F.; Silveira, P.M. Efeitos do sistema de preparo na compactação do solo, disponibilidade hídrica e comportamento do feijoeiro. Pesquisa Agropecuária Brasileira, Brasília, v.34, n.1, p.83-91, 1999.

Ungaro, M.R.G.; Dechen, S.C.F.; Quaggio, J.A.; Nnabude, P.C.; Gallo, P.B. Effect of crop rotation on soil chemical conditions and sunflower, soybean and maize production. Helia, Novi Sad, v.23, p.1-18. 2000.

Ungaro, M.R.G.; Ambrosio, L.A.; Peche Filho, A.; Calvet, N.P.; Lino, A.C.L.; Rossetto, R. Sunflower performance at plough out sugar cane areas in Brazil. Simposium on Sunflower in Developing Countries, 2, 2002, Benoni, South Africa. Proceedings... Paris, 2002. www.cetiom.fr/isa/. 03 dez. 2002.

Vieira, M.J. Propriedades físicas do solo. In: Plantio direto no Estado do Paraná. Londrina: IAPAR, 1981. p.19-32. Circular IAPAR, 23 